\title{
Funded Principal Investigator
}

National Cancer Institute

\section{Source}

National Cancer Institute. Funded Principal Investigator. NCI Thesaurus. Code C63403.

The investigator named on the award document. This investig ator has full and ultimate responsibility for all research conducted under the award. 